\title{
Synthesis and Application of Efficient and Environment-friendly PAE Resin
}

\author{
Chong Han ${ }^{1,}$, Chuanshan Zhao ${ }^{1, b}$ \\ ${ }^{1}$ Ministry of Education Key Laboratory of Pulp and Paper Science and Technology, Qilu University \\ of Technology, Jinan, 250353, China \\ aemail:hanchog@163.com, bemail:ppzcs78@163.com
}

Keywords: PAE; Complex Fatty Acid Ester; Organic Chloride; Wet Strength

\begin{abstract}
According to the problem that harmful by-products which are low molecular weight organic chlorides in the synthesis of PAE resin is inevitably, in order to reduce the content of organic chlorine, complex fatty acid ester was used as a modifier to compound new PAE (N-PAE) resin, as such, the active amount of polyamide and epoxy propane became less, so the viscosity of PAE resin was supposed to increase to certain high extent without gel to ensure performance while using complex fatty acid ester to enter PAE molecule chain to form a low-energy surface and reduce the resistance to motion between PAE molecules. In that case, we just need relatively less $\mathrm{N}$-PAE resin to match or even exceed the normal market PAE resin.
\end{abstract}

\section{Introduction}

PAE resin, called polyamide epichlorohydrin, is one of the most commonly used in the paper industry as a wet strength agent, it is widely used in a variety of paper sheet, giving the paper better wet strength, and even in sanitary paper [1,2]. PAE resin is water-soluble, cationic and thermosetting, it has the characteristics of wide range of applications, high strength of paper and lower toxicity. The paper sheet added PAE resin needs curing to get maximum wet strength, and the solid content of PAE resin on the market is $12.5 \%$ normally $[3,4]$.

PAE resin is generated by the polyamide and epichlorohydrin, and the polyamide (PPC) is generated by a condensation reaction of diethylenetriamine and adipic acid [5]. However, epichlorohydrin can't completely convert to the active moiety of PAE resin, and then by-products appear inevitably. These by-products are some of the low molecular weight organic chlorides, such as 1,3-epichlorohydrin (1,3-DCP), 3-ethyl-chloro-1,2-ol (3-MCPD), which are toxic [6]. In addition, the higher viscosity of PAE resin is, the better the effect of paper wet strength, but if the viscosity is too high, PAE resin will lose water solubility and cannot be used $[7,8]$. In order to reduce the content of organic chlorides, we used the modifier complex fatty acid ester to prepare moderately high viscosity PAE resin without gel and make this new PAE (N-PAE) resin have not only lower organic chlorides content but also better performance in papermaking. Fatty acid ester has poor water-solubility, complex fatty acid ester with the help of surfactant can be dispersed in water, and, of course, PAE resin itself is a surfactant. The effect of application was discussed as follows.

\section{Materials and Instruments}

Diethylenetriamine, A.R; Adipic acid, A.R; Epichlorohydrin, A.R; Catalyst; Complex fatty acid ester (self-made); Hydrochloric acid, A.R; Softwood pulp (40SR, Asia Symbol Pulp and Paper).

Three-necked flask (500ml); Spherical condensing tube; Thermometer; Dropping funnel; Rotational viscometer (NDJ-5S); Kaiser papermaking machine; Electro-thermostatic blast oven; Schopper tensile strength tester.

\section{Experiments}

\section{Synthesis of prepolymer (PPC)}

The prepolymer (PPC) is Polyamide, the molar ratio of diethylenetriamine and adipic acid was 1 : 
1.05, then a small amount of catalyst was added, next the system began to heat to $165^{\circ} \mathrm{C}$ in silicone oil bath and keep this temperature for 4 hours, finally hot water was filled in the three-necked flask until the solid content of prepolymer was 50\%. The reaction mechanism was as below:

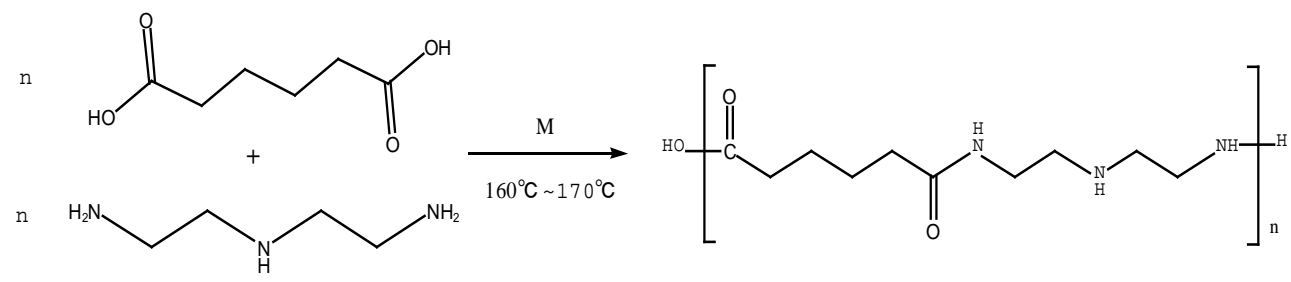

\section{Epoxidation}

The common-viscosity N-PAE resin: The system of PPC above was cooled to $40^{\circ} \mathrm{C}$, epoxy propane, complex fatty acid ester and some water were added slowly, the weight ratio of epoxy propane, complex fatty acid ester was $1: 1$, then the temperature of new system was heated to $60^{\circ} \mathrm{C}$, hydrochloric acid was used to stop the reaction when the viscosity tested by rotational viscometer was $20 \mathrm{mPa} \cdot \mathrm{s}\left(25^{\circ} \mathrm{C}\right)$, the $\mathrm{PH}$ value of PAE resin was adjusted to $4-5$, finally water was added until the solid content was $7.0 \%$.

The high-viscosity N-PAE resin: Followed by the previous step, phydrochloric acid was used to stop the reaction when the viscosity tested by rotational viscometer was $50 \mathrm{mPa} \cdot \mathrm{s}$, the $\mathrm{PH}$ value of PAE resin was adjusted to 4-5, finally water was added until the solid content was $7.0 \%$. The reaction mechanism was as below:

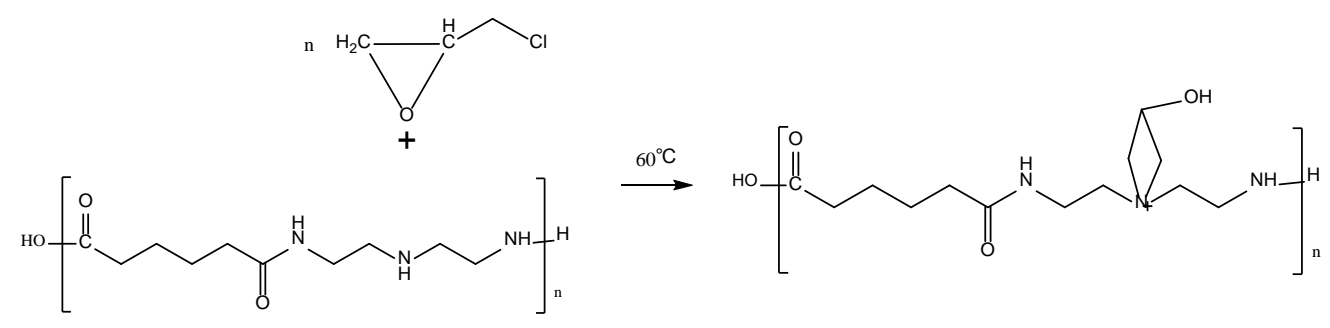

\section{Application}

Paper basis weight was $80 \mathrm{~g} / \mathrm{m}^{2}$, the addition amount of PAE resin was $0.8 \%$ and $0.5 \%$ (to oven dry stock) in papermaking. It was considered to be cured completely when paper sheet was dried at $105^{\circ} \mathrm{C}$ for 30 minutes [9]. Performance was mainly the wet tensile strength of paper by Schopper tensile strength tester.

\section{Results and Discussion}

Table 1 The viscosity of three kinds of PAE resin

\begin{tabular}{|l|c|c|c|}
\hline Sample & Market PAE & Common-viscosity N-PAE & High-viscosity N-PAE \\
\hline Viscosity $(\mathrm{mPa} \cdot \mathrm{s})$ & 20 & 20 & 50 \\
\hline
\end{tabular}

PAE resin as a wet strength agent can not only improve the wet strength but also the dry strength [10]. As was shown in Fig. 1 and 2, when the market PAE resin as reference was added $0.8 \%$, the dry strength ratio improved was $18 \%$, which was better than that of common-viscosity N-PAE resin when added $0.5 \%$ and $0.8 \%$ but worse than that of high-viscosity N-PAE when added $0.5 \%$, let alone high-viscosity N-PAE when added $0.8 \%$. It was mainly because though the viscosity of N-PAE was higher, the active moiety of N-PAE resin was less than market PAE resin, however, the longer molecular chains of high-viscosity N-PAE could make up this deficiency. So it was more efficient obviously to use high-viscosity N-PAE resin in place of normal market PAE resin, in which case the dry strength only added $0.5 \% \mathrm{~N}$-PAE resin could match or even exceed that of market PAE resin added $0.8 \%$. 


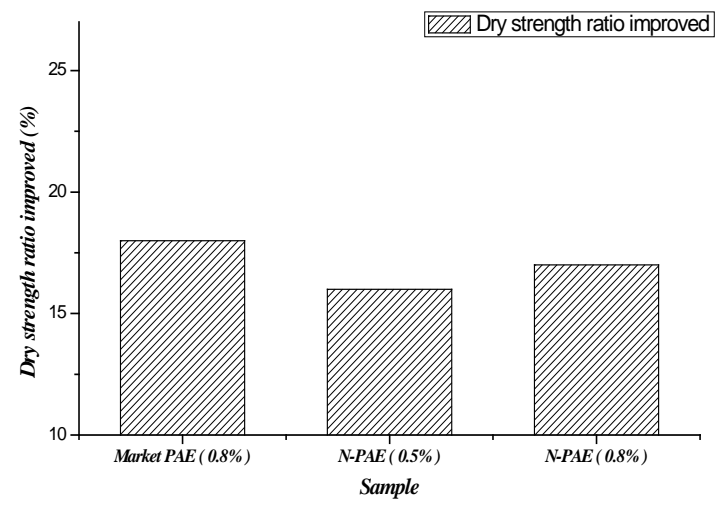

Fig. 1 Comparison of common-viscosity N-PAE and market PAE resin in dry strength ratio improved

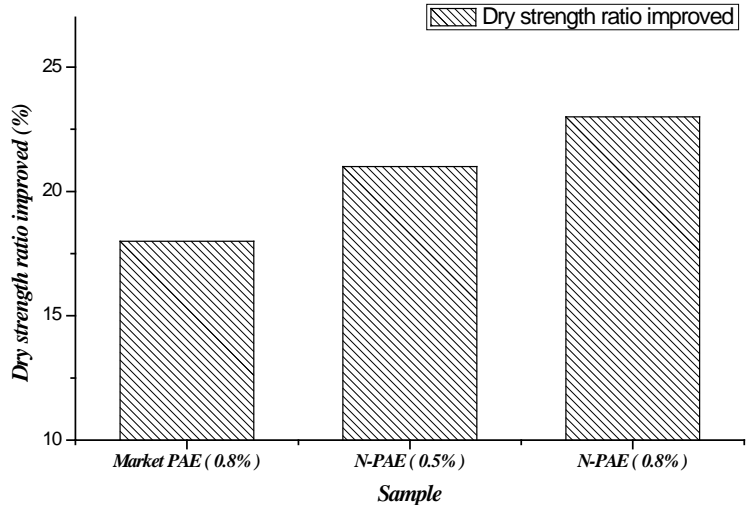

Fig. 2 Comparison of high-viscosity N-PAE and market PAE resin in dry strength ratio improved

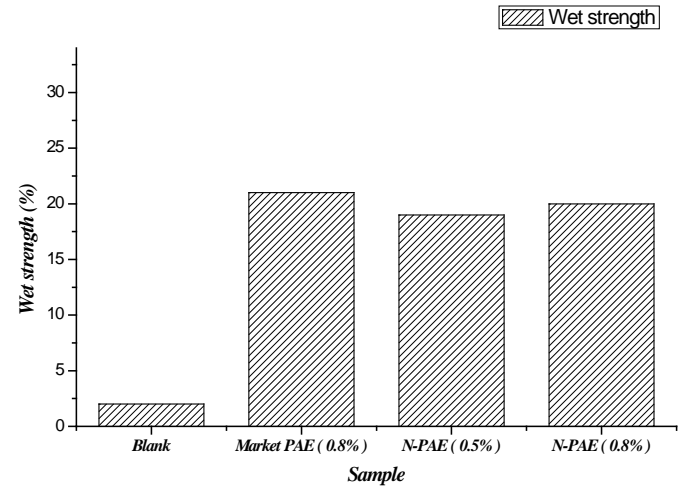

Fig. 3 Comparison of common-viscosity N-PAE and market PAE resin in wet strength

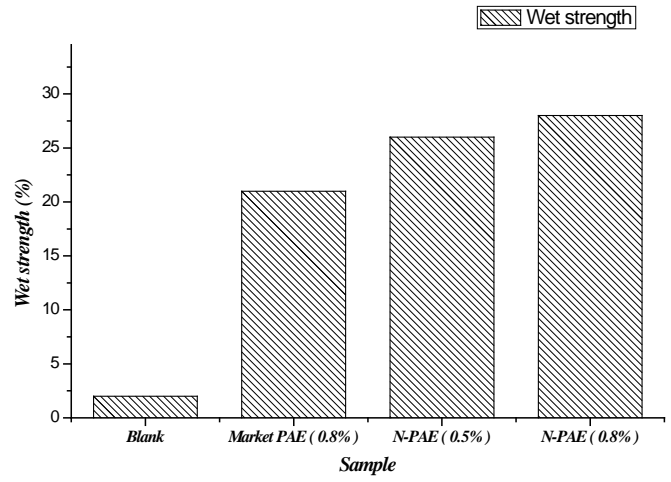

Fig. 4 Comparison of high-viscosity N-PAE and market PAE resin in wet strength 
Wet strength is the ratio of wet-strength force and dry-strength force in the same air humidity. The paper sheet without adding wet strength agent had low wet strength, which was about $2 \%$, as shown Fig. 3, the wet strength of market PAE resin improved to $21 \%$, the two kinds of common-viscosity N-PAE resin were $19 \%$ and $20 \%$, It was also because the complex fatty acid ester acted as a partial of solid content, the actual amount of PPC and epoxy propane was relatively less.

PAE resin with higher viscosity has better performance in paper wet strength, the reason is that linear and branched chain of PAE molecule grow to a certain extent, making it easy to obtain more crosslinking between PAE molecules, PAE molecule and hydroxy of cellulose, hemicellulose. Fig. 4 showed that the wet strength was $26 \%$ when the high-viscosity N-PAE resin was added $0.5 \%$, which was 5\% higher than market PAE resin clearly, though it was 7\% higher than market PAE resin when added $0.8 \%$, enhancement efficiency turned out to be low. The reason why N-PAE resin could achieve high viscosity without gel was that fatty acid ester compound entered PAE molecule chain to form a low-energy surface with lubricating, reducing the resistance to motion between PAE molecules. Thus, the more efficient and environment-friendly method to get satisfactory performance was in the case of $0.5 \%$ high-viscosity N-PAE resin.

\section{Conclusion}

This article provided an efficient method for preparing efficient and environment-friendly PAE resin, that was, using complex fatty acid ester as a modifier to compound new PAE resin in order to reduce the content of organic chlorine in PAE resin to protect the environment and increase the viscosity to certain high extent without gel to ensure performance in papermaking. When the high-viscosity N-PAE resin was added $0.5 \%$, the enhancement effect was better than normal market PAE resin added $0.8 \%$ no matter of dry strength or wet strength, in addition to high efficiency and environmental protection, the cost of synthesis was also lower if it replaced a portion of polyamide and epoxy propane.

\section{References}

[1] Zhou Jinghui, Wu Xing'e. Progress of Wet Strength Agent in Paper Industry [J]. China Pulp \& Paper, 2003, 22 (09) 52-55.

[2] Shen Yiding, Peng Xiaoling. Shen Y D. Research Progress of the Modification and Application of Polyaminamide Epichlorohydrin Resin [J]. China Pulp \& Paper, 2005, 24 (04) 55-58.

[3] J. C. Roberts. Applications of Paper Chemistry [M]. Springer Netherlands, 1991.

[4] Yang Qin, Xue Guoxin, Zhang Xiumei. The Wet-Strengthening Additives in Papermaking [J]. Paper \& Paper Making, 200625 (04) 34-37.

[5] Yan Weibo, Wang Jian, Wang Zhijie, Kang Yan, Li Yao. Study on the Modified PAE Resin as Paper Strengthening Agents [J]. Transactions of China Pulp \& Paper, 2014, 29 (02) 14-17.

[6] Deng Min, Fu Shiyu, Zhan Huaiyu. Research Progress of Environment-friendly Wet Strength Agent for Papermaking [J]. China Pulp \& Paper, 2009, 28 (03) 62-66.

[7] Wang Jian, Qi Liang, Zhou Xiaowei. Migration of PAE in Paper Drying [J]. China Pulp \& Paper, 2008, 27 (07) 29-31.

[8] Fei Guiqiang, Shen Yiding, Wang Haihua, Li Ganghui, Chen Yuqun. Effect of Relative Molecular Weight of Modified EA/WEP/PAE Wet-Strength Agent on Its Properties [J]. Transactions of China Pulp \& Paper, 2008, 23 (01) 73-76.

[9] Pang Jinjiang, Zhao Chuanshan, Zhu Qing, Tang Jiebin. Preparation of New Type Polyamide-Polyamine Epichlorohydrin Resin and Its Application in Papermaking [J]. Paper \& Paper Making, 2010, 29 (02) 27-30.

[10] Wang Lifang. Research and Development of Modified PAE Resin for Paper Dry Strength Agents [D]. 2013. 